\title{
Identifying classes of the pain, fatigue, and depression symptom cluster in long-term prostate cancer survivors-results from the multi-regional Prostate Cancer Survivorship Study in Switzerland (PROCAS)
}

\author{
Salome Adam ${ }^{1,2} \cdot$ Melissa S. Y. Thong ${ }^{3}$ (D) Eva Martin-Diener ${ }^{2} \cdot$ Bertrand Camey $^{4} \cdot$ Céline Egger Hayoz $^{4}$. \\ Isabelle Konzelmann ${ }^{5}$. Seyed Mohsen Mousavi ${ }^{6,7}$. Christian Herrmann ${ }^{6,7}$. Sabine Rohrmann ${ }^{2,8}$. Miriam Wanner ${ }^{2,8}$. \\ Katharina Staehelin ${ }^{9} \cdot$ Räto T. Strebel $^{10}$ - Marco Randazzo ${ }^{11,12} \cdot$ Hubert John $^{12} \cdot$ Hans-Peter Schmid $^{13} \cdot$ Anita Feller $^{1}$. \\ Volker Arndt ${ }^{1,3}$ (D)
}

Received: 18 July 2020 / Accepted: 4 March 2021 / Published online: 13 April 2021

(C) The Author(s) 2021

\begin{abstract}
Purpose Aside from urological and sexual problems, long-term ( $\geq 5$ years after initial diagnosis) prostate cancer (PC) survivors might suffer from pain, fatigue, and depression. These concurrent symptoms can form a cluster. In this study, we aimed to investigate classes of this symptom cluster in long-term PC survivors, to classify PC survivors accordingly, and to explore associations between classes of this cluster and health-related quality of life (HRQoL).

Methods Six hundred fifty-three stage T1-T3N0M0 survivors were identified from the Prostate Cancer Survivorship in Switzerland (PROCAS) study. Fatigue was assessed with the EORTC QLQ-FA12, depressive symptoms with the MHI-5, and pain with the EORTC QLQ-C30 questionnaire. Latent class analysis was used to derive cluster classes. Factors associated with the derived classes were determined using multinomial logistic regression analysis.

Results Three classes were identified: class 1 (61.4\%) - "low pain, low physical and emotional fatigue, moderate depressive symptoms"; class $2(15.1 \%)$ - "low physical fatigue and pain, moderate emotional fatigue, high depressive symptoms"; class 3 (23.5\%) - high scores for all symptoms. Survivors in classes 2 and 3 were more likely to be physically inactive, report a history of depression or some other specific comorbidity, be treated with radiation therapy, and have worse HRQoL outcomes compared to class 1 .
\end{abstract}

Melissa S. Y. Thong

m.thong@dkfz-heidelberg.de

1 National Institute for Cancer Epidemiology and Registration (NICER), c/o University of Zurich, Zurich, Switzerland

2 Division of Chronic Disease Epidemiology, Epidemiology, Biostatistics and Prevention Institute, University of Zurich, Zurich, Switzerland

3 Unit of Cancer Survivorship, German Cancer Research Center (DKFZ), Heidelberg, Germany

4 Fribourg Cancer Registry, Fribourg, Switzerland

5 Health Observatory Valais, Valais Cancer Registry, Sion, Switzerland

6 Cancer Registry East Switzerland, St. Gallen, Switzerland
Cancer Registry Graubünden and Glarus, Chur, Switzerland

8 Cancer Registry Zurich, Zug, Schaffhausen and Schwyz, University Hospital Zurich, Zurich, Switzerland

9 Basel Cancer Registry, Cantonal Department of Health, Basel, Switzerland

10 Department of Urology, Graubünden Cantonal Hospital, Chur, Switzerland

11 Department of Urology, GZO Spital Wetzikon AG, Wetzikon, Switzerland

12 Department of Urology, Winterthur Cantonal Hospital, Winterthur, Switzerland

13 Department of Urology, School of Medicine (Med-HSG), St. Gallen, Switzerland 
Conclusion Three distinct classes of the pain, fatigue, and depression cluster were identified, which are associated with treatment, comorbidities, lifestyle factors, and HRQoL outcomes. Improving classification of PC survivors according to severity of multiple symptoms could assist in developing interventions tailored to survivors' needs.

Keywords Prostate cancer $\cdot$ Classes $\cdot$ Pain $\cdot$ Fatigue $\cdot$ Depression $\cdot$ Symptom cluster

\section{Introduction}

Cancer survivors often suffer from multiple symptoms, depending on their cancer and therapy [1-3]. Numerous studies have already shown that symptoms or the experienced symptom burden impact cancer survivors' health-related quality of life (HRQoL) and clinical outcomes [4]. However, symptom management studies have traditionally focussed only on single symptoms [5], although research indicates that multiple symptoms often coexist and could form symptom clusters $[6,7]$. These symptom clusters can be of therapeutic importance. Treating one symptom of the cluster could influence the others, as the direct treatment of one symptom may indirectly have an impact on another symptom in the cluster $[6,8]$. Consequently, treating one symptom may not necessarily improve HRQoL or prognosis. Therefore, a more profound understanding of symptom clusters and how they affect cancer survivors is necessary.

A symptom cluster has been defined as a stable group of two or more concurrent symptoms that are related and distinct from other symptom clusters [7]. Symptom cluster composition can differ by age, sex, performance status, and cancer diagnosis $[9$, 10]. Moreover, the presence of specific clusters and the number and severity of symptoms are associated with survival/mortality and poorer HRQoL [9, 11-14]. However, most pertinent studies so far relied on data of breast and lung cancer patients [15], whereas information on symptom clusters in other cancer types, for example prostate cancer (PC), is rare.

Long-term (cancer patients surviving the initial diagnosis for $\geq 5$ years [16]) PC survivors may often suffer from pain, fatigue, and depression in addition to common urological and sexual problems [17-19]. Up to $40 \%$ of a heterogeneous group of PC survivors reported to be chronically fatigue after various treatments [20], up to $50 \%$ suffered from chronic pain [21], and post-treatment depression prevalence can be up to $18.5 \%$ [22]. Pain, fatigue, and depression frequently co-occur, and could therefore be considered a symptom cluster [6, 23]. Prevalence of this pain-fatigue-depression cluster ranges from $7 \%$ in survivors of PC [23] to $21.4 \%$ in patients with advanced cancers of the lung or pancreas [6]. However, these studies neither identified classes of this cluster nor categorized survivors into the identified classes. Even though identifying classes of a symptom cluster and better classification of survivors to the identified classes are important to understand which survivor needs more intensive symptom management
[24]. Research investigating the cluster of cognitive disturbance, sleep problems, pain, depression, and fatigue, referred to as the psychoneurological symptom cluster [25] found four distinct subgroups: (1) all low symptoms, (2) high fatigue and low pain, (3) high pain, and (4) all high symptoms [24, 26]. Patients in these subgroups differed with regard to clinical and demographic characteristics. Moreover, the subgroup with low levels of all four symptoms reported the highest HRQoL [24]. However, to our knowledge, no published study has identified classes of the pain-fatigue-depression cluster in PC survivors, even though it is a relatively common symptom cluster [23]. Therefore, in this exploratory analysis, our first objective was to identify possible classes of the pain-fatiguedepression symptom cluster in a large population-based sample of long-term stage T1-T3N0M0 PC survivors. Our second objective was to identify factors associated with the derived classes and explore associations between classes of the cluster and HRQoL.

\section{Methods}

\section{Study design and study population}

Participants were included from the multi-regional Prostate Cancer Survivorship in Switzerland (PROCAS) cohort. Details of the PROCAS study recruitment and data collection design have been described elsewhere [27]. In short, the PROCAS study included 748 long-term (cancer patients surviving the initial diagnosis for $\geq 5$ years) PC survivors younger than 75 years of age at diagnosis and diagnosed between 2006 and 2011. They were identified via six population-based cancer registries (Cancer Registry Fribourg, Cancer Registry Basel, Cancer Registry Graubünden and Glarus, Cancer Registry East Switzerland, Valais Cancer Registry, Cancer Registry Zurich and Zug) covering an underlying population of over 3.4 million inhabitants ( $\sim 40 \%$ of the total population in Switzerland) in both German- and French-speaking Switzerland. The identified PC patients were invited to participate in the study by their treating urologists. Questionnaires and all other study documents were available in German, French, and Italian. Data collection was conducted between 2017 and 2018 by postal questionnaire. Non-respondents received one reminder. Of the 8712 survivors who met the inclusion criteria for the study (Figure S1), 1246 were randomly 
selected for participation, of whom 1194 could be contacted and received an invitation. Finally, 748 returned a completed questionnaire (response rate: $62.2 \%$ ). This analysis was restricted to 653 PC survivors staged T1-T3 N0 and M0 (according to the TNM classification system published by the American Joint Committee on Cancer [28]).

\section{Study measurements}

\section{Fatigue}

The EORTC QLQ-FA12 is a fatigue module developed to complement the European Organization for Research and Treatment of Cancer Quality of Life Core Questionnaire (EORTC QLQ-C30) [29]. The questionnaire consists of ten unidirectional items and two criteria variables. Responses are arranged on a 4-point scale (1: "not at all" to 4: "very much"). Two criteria variables measure the extent to which fatigue interferes with daily activities and social life. Ten items are assigned to three subscales: physical, emotional, and cognitive fatigue. According to EORTC scoring procedures, all scores are standardized to a range of 0 to 100 [30]. Higher scores indicate higher fatigue.

\section{Pain}

Pain was assessed using the pain subscale of the EORTC QLQ-C30. The scale consists of two questions. According to EORTC scoring procedures, all scores are standardized to a range of 0 to 100 [30]. Higher score indicates more pain.

\section{Depressive symptoms}

Depressive symptoms were measured with the Mental Health Inventory (MHI)-5, which is a five-item mental health measure of SF-36 [31]. Responses are arranged on a 5-point scale (1: "always" to 5: "never"). The scores were standardized by linear transformation to a scale ranging from 0 to 100 with higher scores indicating lower level of depressive symptoms. We defined depressive symptoms using a cut-off of $\leq 56$ [32].

\section{HRQoL and PC-specific symptom burden}

We used the five functioning (physical, role, emotional, cognitive, social) and the health status/overall quality of life scales of the EORTC QLQ-C30 questionnaire to assess HRQoL and the PC-specific module QLQ-PR25 to assess the PC-specific symptom burden. The PC-specific EORTC QLQ-PR25 questionnaire includes 25 questions, assessing urinary and bowel symptoms, sexual activity, sexual functioning, and hormonal treatment-related symptoms. Items for the EORTC QLQ-C30 functioning and EORTC QLQPR25 subscales were scored on a scale from 1 (not at all) to
4 (very much), and from 1 (very poor) to 7 (excellent) for items in the health status/overall quality of life scale. Scoring of all instruments was performed according to pertinent scoring manuals $[30,33]$ and scores were linearly transformed to a scale of $0-100$. Higher scores on the functioning scales and global health/QoL indicate better functioning and better health. Higher scores in the EORTC QLQ-PR25 represent a greater symptom burden or a better sexual functioning and more sexual activity.

\section{Demographics, lifestyle, and clinical data}

Cancer registries provided demographic parameters and clinical information such as date of birth, date of diagnosis, and cancer stage. Physicians and cancer registries gave detailed information on treatments, disease progression/relapse (including biochemical and clinical recurrence, and metastasis after diagnosis of primary tumour at time of survey), and other primary tumours. Self-reported information included education, living with partner, nationality, working status, body weight, body height, and physical activity. Furthermore, self-reported experience (yes/no) of the following comorbidities were assessed: depression, arthritis/rheumatism/arthrosis, diabetes, degenerative disc disease, and upper gastrointestinal disease.

\section{Statistics}

For descriptive purposes, we compared clinical and sociodemographic characteristics between respondents and non-respondents using parametric tests. Non-parametric tests were applied when normality and homogeneity assumptions were violated.

As there are no established cut-offs in guidelines regarding the EORTC QLQ-C30 and EORTC QLQ-FA12 questionnaires, we dichotomized the scales of pain and emotional and physical fatigue using the 75 th percentile as cutoff (Table 1) to identify PC survivors who suffered from fatigue or pain. There is a precedence to dichotomize these

Table 1 Distribution of scores for the fatigue (physical, emotional), pain, and depression symptom cluster of respondents $(n=653)$

\begin{tabular}{llll}
$\begin{array}{l}\text { Missing } \\
\text { values }(n)\end{array}$ & Mean score & SE & $\begin{array}{l}75 \text { th interquartile } \\
\text { score }\end{array}$ \\
\hline 5 & 22.3 & 0.9 & 33.3 \\
8 & 10.9 & 1.2 & 11.1 \\
1 & 15.8 & 0.9 & 33.3 \\
3 & 70.3 & 0.6 & 80.0 \\
\hline
\end{tabular}

Higher scores mean higher symptom burden

*For depressive symptoms, the reported cut-off of 56 was used 
scales in order to facilitate the clinical utility of such scores [34]. For mental distress, the established cut-off $\leq 56$ was used [32]. We excluded cognitive fatigue because the scores were very low (skewed to the left), suggesting that PC survivors in our sample do not have complaints on this aspect of fatigue. Deriving descriptions of the identified classes was performed based on visual comparison, as it was done in comparable papers [24, 26, 35]. Correlations were calculated to assess whether items were interrelated with HRQoL scales.

We performed latent class analysis (LCA) to identify groups of PC survivors with similar profiles of the painfatigue-depression symptom cluster. LCA is a probabilistic clustering approach that aims to obtain the smallest number of groups with similar profiles based on a categorical latent variable [36]. We used the four dichotomized scores of pain, depressive symptoms, and emotional and physical fatigue. The optimal number of latent classes was based on the model with the lowest Bayesian information criterion (BIC) value, indicating the best fit. Respondents were assigned to the class for which the posterior probability was highest.

Multinomial logistic regression was used to identify factors that discriminate between the identified classes. For these models, predictor variables were dichotomized [37]. As we were interested in the independent effect of each variable, we did not adjust for possible confounding in the multinomial logistic regression models in general. However, as age is a strong confounder and could be associated with each independent variable that we tested, sub-analyses were performed for all models adjusting for age (data not shown).

Multivariable linear models were calculated to describe and test for differences in HRQoL by the identified classes. These models were adjusted for cancer stage, age at survey, time since diagnosis, and external-beam radiation therapy. Other variables such as androgen deprivation therapy and radical prostatectomy were considered additional potential confounders but were not included in the final models as they did not improve the model fit (maximum likelihood test with $p<0.1$ ). Independent variables were checked for multicollinearity by calculating the variance inflation factors (VIF) in all models. The $p$-values were not adjusted for multiple testing and refer to the individual tests rather than a global test for differences. All analyses were performed using STATA statistical software (version 15.1).

\section{Ethics}

The PROCAS study was approved as a multi-centre study by the Ethics Committee Zurich and by all reviewer boards accountable for the participating cancer registries (BASEC Number: 2016-00608).

\section{Results}

Mean age at survey was $72.9(\mathrm{SD}=6.3)$ years and mean time since diagnosis 7.6 years $(\mathrm{SD}=1.5)$ (Table 2$)$. A majority of participants were Swiss, living with their partner, and had cancer stage T2N0M0. Respondents were statistically significantly younger ( $p=0.023$ ) than non-respondents, as well as more likely to be Swiss $(p=0.001)$, and to live with their partner $(p=0.045)$. Most participants were treated with radical prostatectomy $(76.7 \%)$, followed by external-beam radiation therapy $(29.6 \%)$.

Table 2 Characteristics of respondents and non-respondents

\begin{tabular}{|c|c|c|c|}
\hline & $\begin{array}{l}\text { Respondents } \\
n=653 \\
\text { Col\% }\end{array}$ & $\begin{array}{l}\text { Non-respondents } \\
n=383 \\
\text { Col } \%\end{array}$ & $p$-value \\
\hline \multicolumn{4}{|l|}{ Age at survey } \\
\hline 70 years & 27.9 & 23.8 & \\
\hline $70-74$ years & 31.4 & 26.9 & \\
\hline $75-79$ years & 24.7 & 31.3 & \\
\hline$\geq 80$ years & 16.1 & 18.0 & 0.029 \\
\hline Mean (SD) & $72.9(6.3)$ & $73.8(6.3)$ & 0.023 \\
\hline Nationality Swiss (yes) & 90.8 & 80.7 & \\
\hline No & 4.1 & 12.8 & \\
\hline Unknown & 5.1 & 6.5 & 0.001 \\
\hline Living with partner (yes) & 70.6 & 62.6 & \\
\hline No & 12.7 & 18.0 & \\
\hline Unknown & 16.7 & 19.4 & 0.045 \\
\hline \multicolumn{4}{|l|}{ Histological grade } \\
\hline 1 & 0.5 & 1.3 & \\
\hline 2 & 46.1 & 50.4 & \\
\hline 3 & 31.7 & 29.8 & \\
\hline Unknown & 21.8 & 18.5 & 0.1003 \\
\hline \multicolumn{4}{|l|}{ Cancer stage } \\
\hline T1N0M0 & 16.9 & 25.1 & \\
\hline T2N0M0 & 64.8 & 54.3 & \\
\hline T3N0M0 & 19.3 & 20.6 & 0.0924 \\
\hline \multicolumn{4}{|l|}{ Years since diagnosis } \\
\hline $5-6$ & 26 & 26.9 & \\
\hline $7-8$ & 44.1 & 29.7 & \\
\hline $9-10$ & 29.9 & 33.4 & 0.537 \\
\hline Mean (SD) & $7.6(1.5)$ & $7.7(1.5)$ & 0.537 \\
\hline \multicolumn{4}{|l|}{ Therapy } \\
\hline Radical prostatectomy & 76.7 & - & \\
\hline $\begin{array}{l}\text { External-beam } \\
\text { radiation therapy }\end{array}$ & 29.6 & - & \\
\hline Brachytherapy & 5.8 & - & \\
\hline $\begin{array}{l}\text { Androgen deprivation } \\
\text { therapy }\end{array}$ & 17.1 & - & - \\
\hline
\end{tabular}

Col column 
Correlations between the pain-fatigue-depression symptom cluster with EORTC QLQ-C30 and EORTC QLQ-PR25 scores were weak to moderate (correlation coefficient, 0.50 to 0.40 ) (Table $\mathrm{S} 2$ ).

\section{Characteristics of identified PNS classes}

Of the four classes identified with LCA, we selected a 3-class solution based on the lowest BIC (Table 3). Ten cases with missing data on at least one of the scales were excluded. Most PC survivors $(n=394,61.4 \%)$ were categorized into class 1 , $98(15.1 \%)$ to class 2 , and $151(23.5 \%)$ to class 3.

Class 1 is characterized by low scores for pain (mean = 10.5), and physical and emotional fatigue, and moderate scores for depressive symptoms (Fig. 1, Table S3). Low physical fatigue and pain scores but moderate emotional fatigue and high depressive symptoms scores characterized class 2 . Class 3 was defined by high scores for all symptoms.

\section{Factors associated with identified pain-fatigue- depression symptom cluster classes}

Multinomial logistic regression revealed that pain-fatiguedepression symptom cluster classes 1 and 2 differed significantly by having reported a depression as comorbidity (Table 4). In comparison with class 1 (low pain, low physical and emotional fatigue, moderate depressive symptoms), PC survivors in class 2 (low physical fatigue, low pain, moderate emotional fatigue, high depressive symptoms) were 9.5 times (95\% CI: 3.94-23.01) more likely to have reported a depression.

When compared to class 1, PC survivors in class 3 (high physical and emotional fatigue, high pain, high depressive symptoms) were more likely to be older $(\mathrm{OR}=1.53$, 95\%CI: $1.05-2.26)$, to be overweight ( $\mathrm{OR}=2.23,95 \% \mathrm{CI}$ : 1.44-3.45), to have degenerative disc disease $(\mathrm{OR}=2.35$, 95\% CI: 1.46-3.80), to have an upper gastrointestinal disease $(\mathrm{OR}=2.11,95 \% \mathrm{CI}: 1.18-3.89)$, to have depression $(\mathrm{OR}=$ 15.97, 95\%CI: 7.19-35.50), and to be treated with externalbeam radiation therapy $(\mathrm{OR}=1.69,95 \% \mathrm{CI}: 1.14-2.51)$. On the other hand, they were less likely to have a partner $(\mathrm{OR}=$ $0.53,95 \%$ CI: $0.31-0.91$ ), to do the recommended $\geq 1.25 \mathrm{~h}$ of vigorous physical activity per week $(\mathrm{OR}=0.45,95 \% \mathrm{CI}$ : $0.30-0.67)$, and to have arthritis/rheumatism/arthrosis (OR = $1.81,95 \%$ CI: $1.18-2.80)$.

Table 3 Optimal number of classes according to Bayesian Information Criterion (BIC)

\begin{tabular}{llll}
\hline & BIC & $p$-value & Entropy \\
\hline 2-cluster & 2640 & $<0.001$ & 0.8190 \\
3-cluster & 2631 & 0.010 & 0.6784 \\
4-cluster & 2633 & 1.000 & 0.6222 \\
\hline
\end{tabular}

When comparing class 2 (reference) and class 3, being overweight $(\mathrm{OR}=2.62,95 \% \mathrm{CI}: 1.50-4.59)$, doing less vigorous physical activity per week (OR $=0.46,95 \%$ CI: 0.27 0.79 ), being less likely to be treated with radical prostatectomy (OR $=0.48,95 \%$ CI: $0.25-0.92)$, but more likely to be treated with external-beam radiation therapy $(\mathrm{OR}=2.32,95 \% \mathrm{CI}$ : $1.30-4.17)$ were associated with being in class 3 .

In age-adjusted multinomial logistic regression models, similar effects for each independent variable were observed (data not shown).

\section{Differences in HRQoL and PC-specific symptom bur- den by pain-fatigue-depression symptom cluster classes}

Beside sexual activity, PC survivors in class 1 reported statistically significantly better functioning scores, lower symptom scores, and better sexual functioning (mean difference $=7.2, p$ $=0.003$ ), when compared to survivors of class 3 (Table 5). A similar picture was observed when survivors of class 3 were compared to those of class 2 , except for urinary bother (mean difference $=-3.3, p=0.437$ ), sexual activity (mean difference $=$ $-0.7, p=0.672$ ), and sexual functioning (mean difference $=-$ $0.8, p=0.981$ ) where no difference was observed. In comparison to survivors of class 1 , survivors of class 2 indicated statistically significantly lower global health (mean difference $=6.8, p<$ 0.001 ) and functioning scores but similar physical functioning (mean difference $=-0.1, p=0.963$ ). Regarding symptoms, survivors in class 2 reported higher burden for urinary symptoms (mean difference $=-4.4, p=0.015$ ), bowel symptoms (mean difference $=-2.9, p=0.009$ ), hormone treatment-related symptoms (mean difference $=-5.0, p<0.001$ ), and worse sexual functioning (mean difference $=8.0, p=0.005$ ). All VIF in these models were below 2 .

\section{Discussion}

In this study, we identified three classes of the painfatigue-depression symptom cluster. The majority of long-term PC survivors had no problems with pain, physical, and emotional fatigue, but had moderate depressive symptoms (class 1). The other two painfatigue-depression symptom classes were characterized by having high depressive symptoms and a higher burden of emotional fatigue. The result of our study indicates that different classes of the pain-fatigue-depression symptom cluster exist are in line with previous studies $[24,26]$.

It is interesting that we observed a strong difference in only one fatigue dimension between class 1 and class 2 . Physical fatigue was similarly low in both classes, but emotional fatigue, which had a mean score of 0 in class 1 , was higher 


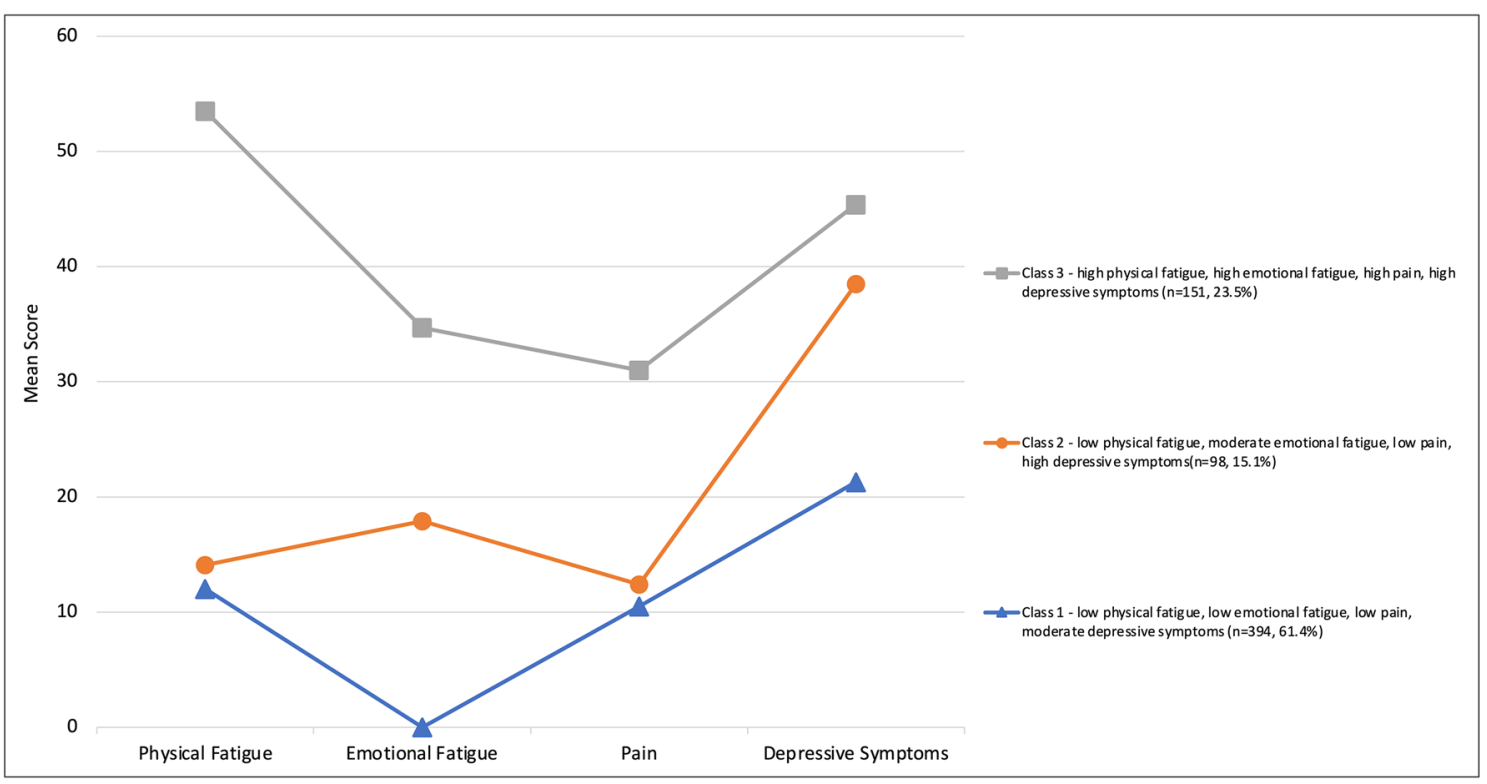

* Score is the reverse of the depressive symptom score for better comparability to the other scores

Fig. 1 Mean scores of physical fatigue, emotional fatigue, pain, and depressive symptoms*, by class of pain-fatigue-depression cluster.

(mean score of 17.9) in class 2. Moreover, the depressive symptoms mean score in class 2 (38.5) was almost double that of class 1 (21.3), whereas the mean score for pain was equally low in both classes. This is in line with the fact that the only factor which differentiated survivors between class 1 and class 2 was "having a depression". In the EORTC QLQ-FA12, emotional fatigue is an expression of "lack of motivation" which is likely to partly overlap with items in the MHI-5 questionnaire assessing motivation and possible anhedonia (lack of positive aspects). As different dimensions of fatigue can lead to different clinical outcomes, this highlights the importance of accurate differential diagnosis for effective clinical management of these symptoms [38, 39].

Moreover, PC survivors in class 3 suffered significantly from other specific comorbidities besides depression (e.g. degenerative disc disease and upper gastrointestinal disease) than PC survivors in class 1, whereas no significant odds ratios for these comorbidities were found when comparing PC survivors of class 1 and class 2 . As the prevalence of comorbidities and intensity of fatigue are associated [40], this result is underlined by the large difference in the physical fatigue score between class 1 (mean 12.0) and class 3 (mean 53.5). This result regarding comorbidities is noteworthy, especially in view of previous research showing that there is a potential association between fatigue and increased risk of allcause mortality in male colorectal cancer survivors, in particular in those with comorbid heart disease [41].

Interestingly, two characteristics that differentiated survivors between class 2 and class 3 were doing more than $1.5 \mathrm{~h}$ of vigorous physical activities per week and being obese, such that PC survivors of class 2 were more active and had a lower
BMI. These results are comparable with Kim et al. [26], who also observed that subgroups differed regarding physical activity status, and with Thong et al. [35], who reported that overweight/obese colorectal cancer survivors were more likely to be classified in the high fatigue group. Therefore, these data show the need for promoting a physically active lifestyle in order to reduce fatigue and depressive symptoms [42].

Being in class 3 was also associated with higher odds of external-beam radiation therapy (even after adjustment for stage and age (data not shown)), potentially due to long-term adverse treatment effects such as lower poorer sexual functioning and urinary or bowel problems. These problems can persist [43] and remain of concern years after treatment has ended [44]. Persistence of these symptoms is associated with treatment regret [44] and perceptions of faecal or urine body odour were associated with depressive symptoms [45]. In our sample, men in class 3 reported more treatment-related symptoms and were more likely to have comorbid depression.

Overall, PC survivors in class 3 reported significantly lower scores for all functioning subscales and higher symptom burden when compared with classes 1 and 2. Similar trends were observed when comparing classes 1 and 2, whereas PC survivors of class 2 reported significantly poorer scores for some functioning and symptom scale scores. These results are not entirely surprising as we have expected that PC survivors with higher burden from multiple symptoms have decreased HRQoL functioning, similar to a previous study on classes of cancer-related fatigue [35]. However, we were surprised by the extent of the mean HRQoL differences as these were much larger than differences in HRQoL by treatment, age, or years since diagnosis in a similar population $[18,19]$. 
Table 4 Odd ratios and 95\% CIs of factors associated with latent classes of pain-fatigue-depression cluster

\begin{tabular}{llll}
\hline $\begin{array}{l}\text { Class } 2 \text { vs. } \\
\text { class } 1 *\end{array}$ & $\begin{array}{l}\text { Class } 3 \text { vs. } \\
\text { class } 1 *\end{array}$ & \multicolumn{2}{l}{$\begin{array}{l}\text { Class } 3 \text { vs. class } \\
2 *\end{array}$} \\
\cline { 1 - 3 } OR $95 \% \mathrm{CI}$ & OR $95 \% \mathrm{CI}$ & OR $95 \% \mathrm{CI}$
\end{tabular}

Age (years) at time of survey ${ }^{1}$

$\begin{array}{lllllll}<73 & 1 & & 1 & & 1 & \\ \geq 73 & 0.81 & 0.51-1.31 & \mathbf{1 . 5 3} & \mathbf{1 . 0 5}-\mathbf{2 . 2 6} & 1.69 & 0.96-3.00\end{array}$

Education (highest degree)

\begin{tabular}{lllllll}
$\begin{array}{c}\text { Low and } \\
\text { medium }\end{array}$ & 1 & & 1 & \multicolumn{3}{c}{1} \\
High & 0.92 & $0.59-1.44$ & 0.92 & $0.51-1.09$ & 0.81 & $0.48-1.36$
\end{tabular}

Nationality Swiss

$\begin{array}{lllllll}\text { No } & 1 & & 1 & & 1 & \\ \text { Yes } & 1.41 & 0.40-4.91 & 0.57 & 0.26-1.25 & 0.41 & 0.11-1.50\end{array}$

Having a partner

\begin{tabular}{lllllll} 
No & 1 & & 1 & \multicolumn{3}{l}{1} \\
Yes & 1.03 & $0.48-2.20$ & 0.53 & $\mathbf{0 . 3 1 - 0 . 9 1}$ & 0.52 & $0.23-1.16$
\end{tabular}

Working at survey

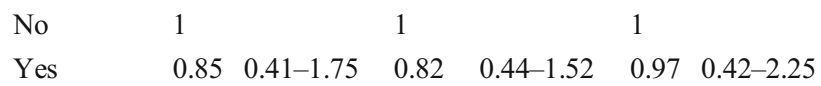

Body mass index

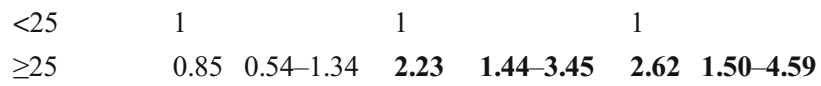

Vigorous physical activities (hours per week) ${ }^{2}$

$\begin{array}{llllllll}<1.25 & 1 & & 1 & & 1 & \\ \geq 1.25 & 0.97 & 0.61-1.53 & \mathbf{0 . 4 5} & \mathbf{0 . 3 0}-\mathbf{0 . 6 7} & \mathbf{0 . 4 6} & \mathbf{0 . 2 7}-\mathbf{0 . 7 9}\end{array}$

Light physical activities (hours per week) ${ }^{1}$

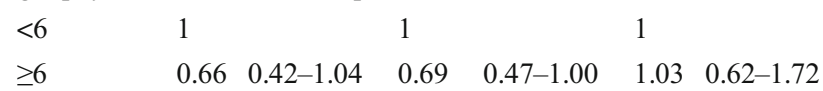

Cancer stage

T1-T2N0M0 1

T3N0M0 $\quad 0.76 \quad 0.41-1.41 \quad 1.20 \quad 0.96-1.51 \quad 1.92 \quad 0.98-3.79$

Years since diagnosis

$$
\begin{array}{lllllll}
5-7 \text { years } & & & & & & \\
8-10 \text { years } & 0.81 & 0.52-1.26 & 1.00 & 0.82-1.20 & 1.22 & 0.73-2.04 \\
\text { Disease progression/relapse } & & & & &
\end{array}
$$

\begin{tabular}{lllllll} 
No & 1 & & 1 & \multicolumn{3}{l}{1} \\
Yes & 1.40 & $0.83-2.37$ & 1.09 & $0.68-1.75$ & 0.78 & $0.43-1.44$
\end{tabular}

Most common comorbidities

Arthritis/rheumatism/arthroses

\begin{tabular}{lllllll} 
No & 1 & & 1 & \multicolumn{3}{c}{1} \\
Yes & 1.22 & $0.72-2.08$ & 1.81 & $1.18-2.80$ & 1.48 & $0.82-2.68$
\end{tabular}

Degenerative disc disease

No

Yes $\quad \begin{array}{llllll}1.25 & 0.67-2.33 & \mathbf{2 . 3 5} & \mathbf{1 . 4 6}-\mathbf{3 . 8 0} & 1.89 & 0.97-3.68\end{array}$

Upper gastrointestinal disease

\begin{tabular}{|c|c|c|c|c|c|c|}
\hline & \multicolumn{2}{|c|}{$\begin{array}{l}\text { Class } 2 \text { vs. } \\
\text { class } 1 *\end{array}$} & \multicolumn{2}{|c|}{$\begin{array}{l}\text { Class } 3 \text { vs. } \\
\text { class } 1 *\end{array}$} & \multicolumn{2}{|c|}{$\begin{array}{l}\text { Class } 3 \text { vs. class } \\
2^{*}\end{array}$} \\
\hline & OR & $95 \% \mathrm{CI}$ & OR & $95 \% \mathrm{CI}$ & OR & $95 \% \mathrm{CI}$ \\
\hline \multicolumn{7}{|c|}{ Diabetes } \\
\hline No & 1 & & 1 & & 1 & \\
\hline Yes & 1.07 & $0.48-2.41$ & 1.78 & $0.97-3.26$ & 1.66 & $0.69-3.96$ \\
\hline \multicolumn{7}{|c|}{ Depression } \\
\hline No & 1 & & 1 & & 1 & \\
\hline Yes & 9.52 & 3.94-23.01 & 15.97 & $7.19-35.50$ & 1.67 & $0.87-3.25$ \\
\hline \multicolumn{7}{|c|}{ Therapy } \\
\hline \multicolumn{7}{|c|}{ Radical prostatectomy } \\
\hline No & 1 & & 1 & & 1 & \\
\hline Yes & 1.45 & $0.79-2.65$ & 0.70 & $0.45-1 \theta .80$ & 0.48 & $0.25-0.92$ \\
\hline \multicolumn{7}{|c|}{ External-beam radiation therapy } \\
\hline No & 1 & & 1 & & 1 & \\
\hline Yes & 0.73 & $0.43-1.24$ & 1.69 & $1.14-2.51$ & 2.32 & $1.30-4.17$ \\
\hline \multicolumn{7}{|c|}{ Brachytherapy } \\
\hline No & 1 & & 1 & & 1 & \\
\hline Yes & 2.01 & $0.88-4.59$ & 1.24 & $0.44-2.80$ & 0.62 & $0.24-1.63$ \\
\hline \multicolumn{7}{|c|}{ Androgen deprivation therapy } \\
\hline No & 1 & & 1 & & 1 & \\
\hline Yes & 1.03 & $0.56-1.91$ & 1.56 & $0.97-2.49$ & 1.51 & $0.77-3.00$ \\
\hline
\end{tabular}

$\begin{array}{lllllll}\text { No } & 1 & & 1 & & 1 & \\ \text { Yes } & 1.82 & 0.91-3.63 & \mathbf{2 . 1 1} & \mathbf{1 . 1 8}-\mathbf{3 . 8 9} & 1.61 & 0.55-2.44\end{array}$

Table 4 (continued)

Odds ratios based on two multinomial logistic regression models, whereas in the first model class 1 was the reference and in a second model class 2 was the reference

*Indicates reference group ${ }^{1}$ cut-off based on median ${ }^{2}$ cut-off based on recommendation of doing at least $1.25 \mathrm{~h} /$ week of vigorous-intensity sport activity

Class 1 - low physical fatigue, low emotional fatigue, low pain, moderate depressive symptoms $(n=364,61.4 \%)$

Class 2 - low physical fatigue, moderate emotional fatigue, low pain, high depressive symptoms $(n=98,51.1 \%)$

Class 3 - high physical fatigue, high emotional fatigue, high pain, high depressive symptoms $(n=151,23.5 \%)$

Missing values are below $<5 \%$

This suggests that HRQoL differences may be better explained by classification of long-term PC survivors to a class of pain-fatigue-depression cluster than based on therapy, age, or time since diagnosis. Regarding PC-specific symptoms, our results are in line with the findings of Baden et al. [23] who investigated the prevalence of the pain-fatigue-depression symptom cluster in PC survivors. Their study showed that PC survivors with all three symptoms were more likely to experience physical symptoms such as incontinence, bowel problems, and symptoms related to androgen deprivation treatment than survivors with $0-2$ symptoms of this cluster. 
Table 5 EORTC QLQ-C30 and PR-25 scores according to the classes of the pain-fatigue-depression symptom cluster

\begin{tabular}{|c|c|c|c|c|c|c|c|c|c|c|c|c|}
\hline & \multicolumn{2}{|c|}{ Class 1} & \multicolumn{2}{|c|}{ Class 2} & \multicolumn{2}{|c|}{ Class 3} & \multicolumn{2}{|c|}{$\begin{array}{l}\text { Difference } \\
\text { Class 1-Class } 2\end{array}$} & \multicolumn{2}{|c|}{$\begin{array}{l}\text { Difference } \\
\text { Class 1-Class } 3\end{array}$} & \multicolumn{2}{|c|}{$\begin{array}{l}\text { Difference } \\
\text { Class 2-Class } 3\end{array}$} \\
\hline & Mean & SE & Mean & SE & Mean & SE & Mean & $\begin{array}{l}p- \\
\text { value }\end{array}$ & Mean & $\begin{array}{l}p- \\
\text { value }\end{array}$ & Mean & $\begin{array}{l}p- \\
\text { value }\end{array}$ \\
\hline \multicolumn{13}{|l|}{ EORTC QLQ-C30 scales } \\
\hline Global health/QoL & 84.0 & 0.8 & 77.2 & 1.7 & 63.6 & 1.4 & 6.8 & $<0.001$ & 20.4 & $<0.001$ & 13.6 & $<0.001$ \\
\hline Physical functioning & 93.9 & 0.8 & 94.0 & 1.4 & 77.9 & 1.1 & -0.1 & 0.963 & 16 & $<0.001$ & 16.1 & $<0.001$ \\
\hline Cognitive functioning & 93.6 & 1.0 & 88.1 & 2.1 & 63.9 & 1.7 & 5.5 & 0.019 & 29.7 & $<0.001$ & 24.2 & $<0.001$ \\
\hline Emotional functioning & 93.7 & 0.8 & 81.2 & 1.5 & 65.9 & 1.2 & 12.5 & $<0.001$ & 27.8 & $<0.001$ & 15.3 & $<0.001$ \\
\hline Role functioning & 90.7 & 0.8 & 84.5 & 1.6 & 74.6 & 1.3 & 6.2 & 0.001 & 16.1 & $<0.001$ & 9.9 & $<0.001$ \\
\hline Social functioning & 92.4 & 1.1 & 83.7 & 2.1 & 71.3 & 1.7 & 8.7 & $<0.001$ & 21.1 & $<0.001$ & 12.4 & $<0.001$ \\
\hline \multicolumn{13}{|l|}{ EORTC QLQ-PR25 scales } \\
\hline Urinary symptoms & 14.4 & 0.8 & 18.8 & 1.6 & 27.4 & 1.2 & -4.4 & 0.015 & -13 & $<0.001$ & -8.6 & $<0.001$ \\
\hline Urinary bother $^{1}$ & 23.1 & 3.3 & 29.5 & 5.3 & 32.8 & 4.4 & -6.4 & 0.381 & -9.7 & 0.037 & -3.3 & 0.437 \\
\hline Bowel symptoms & 3.2 & 0.5 & 6.1 & 1.0 & 11.7 & 0.8 & -2.9 & 0.009 & -8.5 & $<0.001$ & -5.6 & 0.001 \\
\hline Hormonal treatment-related symptoms & 7.5 & 0.5 & 12.5 & 1.1 & 19.6 & 0.8 & $-\mathbf{5 . 0}$ & $<0.001$ & -12.1 & $<0.001$ & -7.1 & $<0.001$ \\
\hline Sexual activity & 43.4 & 1.4 & 38.1 & 2.7 & 38.8 & 2.2 & 5.3 & 0.043 & 4.6 & 0.193 & -0.7 & 0.672 \\
\hline Sexual functioning $^{1}$ & 49.0 & 1.3 & 41.0 & 2.7 & 41.8 & 2.3 & 8.0 & 0.005 & 7.2 & 0.003 & -0.8 & 0.981 \\
\hline
\end{tabular}

EORTC QLQ-C30: higher scores on functioning scales indicate better functioning or global health

EORTC QLQ-PR25: higher score in the EORTC QLQ-PR25 represents a greater symptom burden or better sexual functioning and activity

${ }^{1}$ Smaller sample sizes and no imputation was performed as the questions referring to these scales are conditional

Linear models were adjusted for cancer stage, age at survey, time since diagnosis, and external-beam radiation therapy

Class 1 - low physical fatigue, low emotional fatigue, low pain, moderate depressive symptoms $(n=364,61.4 \%)$

Class 2 - low physical fatigue, moderate emotional fatigue, low pain, high depressive symptoms $(n=98,51.1 \%)$

Class 3 - high physical fatigue, high emotional fatigue, high pain, high depressive symptoms $(n=151,23.5 \%)$

However, as we also found distinct characteristics associated with each class, we believe interventions should be tailored to each pain-fatigue-depression symptom cluster class as Thong et al. [35] suggest for subtypes of the cancer-related fatigue cluster. For example, PC cancer survivors characterized by low physical activity and/or high BMI could profit from an intervention involving advice on nutrition and physical activity [46]. Moreover, exercise, pharmacological, psychoeducation, and mind body therapies could improve fatigue and depression [47, 48].

Further studies of longitudinal design that include and focus on long-term cancer survivors are needed to replicate our results and to investigate how pain-fatigue-depression symptom cluster classes could potentially change over time. For example, the study by Kim et al. suggested that while subgroup composition of the PNS cluster can remain consistent, patients may switch between subgroups over time, or that more subgroups emerge [26]. In PC survivors, HRQoL has been found to be lower during and shortly after treatment but to improve and stabilize thereafter [49, 50]; therefore, it would be interesting to see whether a similar effect as described by Kim et al. would be found in PC survivors.
This study has several limitations. First, as this was an exploratory study, results should be interpreted with caution and need to be replicated in future studies. Second, we used the 75th percentile score cut-off as there are no established cut-offs for the physical and emotional fatigue dimensions of the EORTC QLQ-FA12, and for the EORTC QLQ-C30. However, our values and cut-off for pain are within the range of published interquartile ranges of the chronically ill patients [51]. For the physical and emotional fatigue dimension of the EORTC QLQ-FA12, no literature for a comparable cohort could be found. Third, due to small sample sizes with respect to specific clinical and sociodemographic characteristics, several confidence intervals (Table 4) are wide, resulting in less statistical power for some comparisons. Finally, as fatigue, pain, and depressive symptoms were only assessed at one time point, we could not identify changes over time.

Nevertheless, this is the first study performed in PC survivors identifying classes of the pain-fatigue-depression cluster. Moreover, a multidimensional fatigue questionnaire was used which allowed for differentiation of fatigue dimensions in the identified classes. Additionally, we could assess the association of a broad range of clinical, demographic, and lifestyle characteristics with the identified classes, and the associations 
of the classes with HRQoL and PC-specific symptom burden outcomes.

In conclusion, we found three distinct classes of the pain-fatigue-depression cluster. These classes were associated with treatment, comorbidities and lifestyle factors, and HRQoL outcomes. Therefore, improving classification of PC survivors according to severity of multiple symptoms could assist in developing interventions tailored to survivors' needs to improve HRQoL outcomes.

Supplementary Information The online version contains supplementary material available at https://doi.org/10.1007/s00520-021-06132-w.

Acknowledgements We thank the Swiss Society of Urology, Europa Uomo Switzerland, and the Cancer League Switzerland for the participation and support of the study. Special thanks to all urologists involved for their participation, especially to Dr. Aron Cohen (Küsnacht), Dr. med. Thomas Luginbühl (Uster), Dr. med. Jean-Luc Fehr (Zürich), Dr. med. Ladislav Prikler (Bülach), Dr. med. Dirk Wilbert (Glarus), Dr. med. Friedrich von Toggenburg (Buchs), Dr. med. Thomas Warzinek (Sargans), Dr. med. Stefan Preusser (Wetzikon), Dr. med. Christophe L. Hugonnet (Bulle), Dr. med. Joseph Eigenmann (Fribourg), and Dr. med. Rolf Gerber (Bern).

Code availability The code that supports the findings of this study is available on request from the corresponding author.

Author contribution SA and VA developed the study concept. SA, VA, EMD, and HPS were responsible for the study design. Data acquisition was performed by SA, EMD, BC, CEH, IK, SMM; CH, SR, MQ, KS, RTS, MR, HJ, HPS, and VA.

SA and AF performed the statistical analysis. SA and MT wrote the manuscript. All authors read, commented, and approved the final manuscript.

Funding Open Access funding enabled and organized by Projekt DEAL. The PROCAS study was financially supported by Swiss Bridge. Salome Adam was financially supported by the Béatrice Ederer-Weber Foundation. The funding source was neither involved in the collection, interpretation, and analysis of the data, nor in the decision for the writing of this manuscript.

Data availability The data that support the findings of this study are available on request from the corresponding author. The data are not publicly available due to privacy or ethical restrictions.

\section{Declarations}

Ethics approval The PROCAS study has been approved as a multi-centre study by the Ethics Committee Zurich and by all reviewer boards accountable for the participating cancer registries (BASEC Number: 2016-00608). All procedures involving human participants were in accordance with the Helsinki Declaration of 1975, as revised in 1983.

Consent to participate Informed consent was obtained from all individual participants included in the study.
Consent for publication NA.

Conflict of interest The authors declare no competing interests.

Open Access This article is licensed under a Creative Commons Attribution 4.0 International License, which permits use, sharing, adaptation, distribution and reproduction in any medium or format, as long as you give appropriate credit to the original author(s) and the source, provide a link to the Creative Commons licence, and indicate if changes were made. The images or other third party material in this article are included in the article's Creative Commons licence, unless indicated otherwise in a credit line to the material. If material is not included in the article's Creative Commons licence and your intended use is not permitted by statutory regulation or exceeds the permitted use, you will need to obtain permission directly from the copyright holder. To view a copy of this licence, visit http://creativecommons.org/licenses/by/4.0/.

\section{References}

1. Grossman RL, Heath AP, Ferretti V, Varmus HE, Lowy DR, Kibbe WA et al (2010) The missing voice of patients in drug-safety reporting. N Engl J Med. 363(1):1-3

2. Cleeland CS, Bennett GJ, Dantzer R, Dougherty PM, Dunn AJ, Meyers CA, Miller AH, Payne R, Reuben JM, Wang XS, Lee BN (2003) Are the symptoms of cancer and cancer treatment due to a shared biologic mechanism? Cancer. 97(11):2919-2925

3. National Institutes of Health (2003) Symptom management in cancer: pain, depression and fatigue: State-of-the-Science Conference Statement. J Pain Palliat Care. 17(1):77-97

4. Berry DL (2011) Patient-reported symptoms and quality of life integrated into clinical cancer care. Semin Oncol Nurs. 27(3): 203-210

5. Fan G, Filipczak L, Chow E (2007) Symptom clusters in cancer patients: a review of the literature. Curr Oncol. 14(4):173-179

6. Laird BJA, Scott AC, Colvin LA, McKeon AL, Murray GD, Fearon KCH et al (2011) Pain, depression, and fatigue as a symptom cluster in advanced cancer. J Pain Symptom Manage. 42(1):111

7. Kim H-J, McGuire DB, Tulman L, Barsewick AM (2005) Symptom clusters concept analysis and clinical implications for cancer nursing. Cancer Nurs. 28(4):270-282

8. Walsh D, Rybicki L (2006) Symptom clustering in advanced cancer. Support Care Cancer. 14(8):831-836

9. Jimenez A, Madero R, Alonso A, Mart V, Vilches Y, Mart B (2011) Symptom clusters in advanced cancer. J Pain Symptom Manage. 42(1):24-31

10. Linder L (2015) Analysis of the UCSF symptom management theory: implications for pediatric oncology nursing. J Pediatr Oncol Nurs. 27(6):316-324

11. Lin S, Chen Y, Yang L, Zhou J (2013) Pain, fatigue, disturbed sleep and distress comprised a symptom cluster that related to quality of life and functional status of lung cancer surgery patients. J Clin Nurs. 22(9-10):1281-1290

12. Pirri C, Bayliss E, Trotter J, Olver IN, Katris P, Drummond P et al (2012) Nausea still the poor relation in antiemetic therapy? The impact on cancer patients' quality of life and psychological adjustment of nausea, vomiting and appetite loss, individually and concurrently as part of a symptom cluster. Support Care Cancer 21: 735-748

13. Roiland RA, Heidrich SM (2011) Symptom clusters and quality of life in older adult breast cancer survivors. Oncol Nurs Forum. 38(6): $672-680$ 
14. Wikman A, Johar A, Lagergren P (2014) Presence of symptom clusters in surgically treated patients with esophageal cancer: implications for survival. Cancer. 120(2):286-293

15. Reilly CM, Bruner DW, Mitchell SA, Minasian LM, Basch E, Dueck AC, Cella D, Reeve BB (2013) A literature synthesis of symptom prevalence and severity in persons receiving active cancer treatment. Support Care Cancer. 21(6):1525-1550

16. American Cancer Society. Cancer facts \& figures - 2000. Atlanta: American Cancer Society; 2000

17. Adam S, Feller A, Rohrmann S, Arndt V (2018) Health-related quality of life among long-term ( $\geq 5$ years) prostate cancer survivors by primary intervention: a systematic review. Health Qual Life Outcomes. 16(1):22

18. Adam S, Koch-Gallenkamp L, Bertram H, Eberle A, Holleczek B, Pritzkuleit R, Waldeyer-Sauerland M, Waldmann A, Zeissig SR, Rohrmann S, Brenner H, Arndt V (2019) Health-related quality of life in long-term survivors with localised prostate cancer by therapy - results from a population-based study. Eur J Cancer Care (Engl). 28(5):e13076

19. Adam S, Doege D, Koch-gallenkamp L, Thong MSY, Bertram H, Eberle A et al (2020) Age-specific health-related quality of life in disease-free long-term prostate cancer survivors versus male population controls - results from a population-based study. Support Care Cancer. 28(6):2875-2885

20. Langston B, Armes J, Levy A, Tidey E, Ream E (2013) The prevalence and severity of fatigue in men with prostate cancer: a systematic review of the literature. Support Care Cancer. 21(6):17611771

21. Gerbershagen HJ, Özgür E, Straub K, Dagtekin O, Gerbershagen K, Petzke F, Heidenreich A, Lehmann KA, Sabatowski R (2008) Prevalence, severity, and chronicity of pain and general healthrelated quality of life in patients with localized prostate cancer. Eur J Pain. 12(3):339-350

22. Watts S, Prescott P, Mason J, McLeod N, Lewith G (2015) Depression and anxiety in prostate cancer: a systematic review and meta-analysis of prevalence rates. BMJ Open. 5(11):e007618

23. Baden M, Lu L, Drummond FJ, Gavin A, Sharp L (2020) Pain, fatigue and depression symptom cluster in survivors of prostate cancer. Support Care Cancer. 28(10):4813-4824

24. Miaskowski C, Cooper BA, Paul SM, Dodd M, Lee K, Aouizerat BE et al (2006) Subgroups of patients with cancer with different symptom experiences and quality-of-life outcomes: a cluster analysis. Oncol Nurs Forum. 33(5):79-89

25. Kim HJ, Barsevick AM, Tulman L, McDermott PA (2008) Treatment-related symptom clusters in breast cancer: a secondary analysis. J Pain Symptom Manage. 36(5):468-479

26. Kim H, Barsevick AM, Beck SL, Dudley W (2012) Clinical subgroups of a psychoneurologic symptom cluster in women receiving treatment for breast cancer: a secondary analysis. Oncol Nurs Forum. 39(1):E20-E30

27. Adam S, Martin-Diener E, Schmid H-P, Arndt V (2019) Prostate Cancer Survivorship in Switzerland (PROCAS): study protocol of the Swiss Multiregional Cohort. Schweizer Krebsbulletin. 39:256261

28. Greene FL, Page DL, Fleming ID, Fritz AG, Balch CM, Haller DG et al (2002) AJCC cancer staging manual. 6th ed. AJCC (American Joint Committee on Cancer), editor. Springer-Verlag, New York, $421 \mathrm{p}$

29. Weis J, Tomaszewski KA, Hammerlid E, Ignacio Arraras J, Conroy $\mathrm{T}$, Lanceley A et al (2017) International psychometric validation of an EORTC quality of life module measuring cancer related fatigue (EORTC QLQ-FA12). J Natl Cancer Inst. 109(5):1-8

30. Aaronson NK, Ahmedzai S, Bergman B, Bullinger M, Cull A, Duez NJ, Filiberti A, Flechtner H, Fleishman SB, Haes JCJM, Kaasa S, Klee M, Osoba D, Razavi D, Rofe PB, Schraub S, Sneeuw K, Sullivan M, Takeda F (1993) The European
Organization for Research and Treatment of Cancer QLQ-C30: a quality-of-life instrument for use in international clinical trials in oncology. J Natl Cancer Inst. 85(5):365-376

31. Berwick DM, Murphy JM, Goldman PA, Ware JE, Barsky AJ, Weinstein MC (1991) Performance of a five-item mental health screening test. Med Care. 29(2):169-176

32. Strand BH, Dalgard OS, Tambs K, Rognerud M (2003) Measuring the mental health status of the Norwegian population: a comparison of the instruments SCL-25, SCL-10, SCL-5 and MHI-5 (SF-36). Nord J Psychiatry. 57(2):113-118

33. van Andel G, Bottomley A, Fosså SD, Efficace F, Coens C, Guerif S, Kynaston H, Gontero P, Thalmann G, Akdas A, D'Haese S, Aaronson NK (2008) An international field study of the EORTC QLQ-PR25: a questionnaire for assessing the health-related quality of life of patients with prostate cancer. Eur J Cancer. 44(16):2418 2424

34. Diouf M, Bonnetain F, Barbare J-C, Bouche O, Dahan L, Paoletti X et al (2015) Optimal cut points for quality of life questionnaire-core 30 (QLQ-C30) scales: utility for clinical trials and updates of prognostic systems in advanced hepatocellular carcinoma. Oncologist. 20(1):62-71

35. Thong MSY, Mols F, van de Poll-Franse LV, Sprangers MAG, van der Rijt CCD, Barsevick AM, Knoop H, Husson O (2018) Identifying the subtypes of cancer-related fatigue: results from the population-based PROFILES registry. J Cancer Surviv. 12(1):3846

36. Vermunt JK, Magidson J (2002) Latent class cluster analysis. Appl Latent Cl Anal. 2009:89-106

37. Ferrat E, Audureau E, Paillaud E, Liuu E, Tournigand C, Lagrange JL, Canoui-Poitrine F, Caillet P, Bastuji-Garin S, on behalf of the ELCAPA Study Group (2016) Four distinct health profiles in older patients with cancer: latent class analysis of the prospective elcapa cohort. J Gerontol - Ser A Biol Sci Med Sci. 71(12):1653-1660

38. Howell D (2003) Screning and assessment - fatigue in cancer survivors. Curr Oncol. 20(3):e242-e243

39. Andersen BL, DeRubeis RJ, Berman BS, Gruman J, Champion VL, Massie MJ, Holland JC, Partridge AH, Bak K, Somerfield MR, Rowland JH, American Society of Clinical Oncology (2014) Screening, assessment, and care of anxiety and depressive symptoms in adults with cancer: an American Society of Clinical Oncology guideline adaptation. J Clin Oncol. 32(15):1605-1619

40. Yates P, Miaskowski C, Cataldo JK, Paul SM, Cooper BA, Alexander K, Aouizerat B, Dunn L, Ritchie C, McCarthy A, Skerman H (2015) Differences in composition of symptom clusters between older and younger oncology patients. J Pain Symptom Manage. 49(6):1025-1034

41. Adam S, van de Poll-Franse LV, Mols F, Ezendam NPM, de Hingh IHJT, Arndt V et al The association of cancer-related fatigue with all-cause mortality of colorectal and endometrial cancer survivors: results from the population-based PROFILES registry. Cancer Med 8(6):3227-3236

42. Eyl RE, Koch-Gallenkamp L, Jansen L, Walter V, Carr PR, Hoffmeister $\mathrm{M}$ et al Physical activity and long-term quality of life among colorectal cancer survivors - a population-based prospective study. Cancer Prev Res 13(7):611-622

43. Mols F, Korfage IJ, Vingerhoets AJJM, Kil PJM, Coebergh JWW, Essink-Bot ML, van de Poll-Franse LV (2009) Bowel, urinary, and sexual problems among long-term prostate cancer survivors: a population-based study. Int J Radiat Oncol Biol Phys. 73(1):30-38

44. Hoffman RM, Lo M, Clark JA, Albertsen PC, Barry MJ, Goodman M, Penson DF, Stanford JL, Stroup AM, Hamilton AS (2017) Treatment decision regret among long-term survivors of localized prostate cancer:rResults from the prostate cancer outcomes study. J Clin Oncol. 35(20):2306-2314

45. Alsadius D, Olsson C, Pettersson N, Tucker SL, Wilderäng U, Steineck G (2013) Perception of body odor-an overlooked 
consequence of long-term gastrointestinal and urinary symptoms after radiation therapy for prostate cancer. J Cancer Surviv Res Pract. 7(4):652-658

46. Ballon-landa E, Parsons JK (2018) Nutrition, physical activity, and lifestyle factors in prostate cancer prevention. Curr Opin Urol. 28(1):55-61

47. Pearson EJM, Morris ME, di Stefano M, McKinstry CE (2018) Interventions for cancer-related fatigue: a scoping review. Eur J Cancer Care (Engl). 27(1):e12516

48. Rodin G, Katz M, Lloyd N, Green E, Mackay JA, Wong RKS, the Supportive Care Guidelines Group of Cancer Care Ontario's Program in Evidence-Based Care (2007) Treatment of depression in cancer patients. Curr Oncol. 14(5):180-188

49. Donovan JL, Hamdy FC, Lane JA, Mason M, Metcalfe C, Walsh E, Blazeby JM, Peters TJ, Holding P, Bonnington S, Lennon T, Bradshaw L, Cooper D, Herbert P, Howson J, Jones A, Lyons N, Salter E, Thompson P, Tidball S, Blaikie J, Gray C, Bollina P, Catto
J, Doble A, Doherty A, Gillatt D, Kockelbergh R, Kynaston H, Paul A, Powell P, Prescott S, Rosario DJ, Rowe E, Davis M, Turner EL, Martin RM, Neal DE, ProtecT Study Group (2016) Patient-reported outcomes after monitoring, surgery, or radiotherapy for prostate cancer. N Engl J Med. 375(15):1425-1437

50. Namiki S, Kaiho Y, Mitsuzuka K, Saito H, Yamada S, Nakagawa H (2014) Original Article : Clinical investigation long-term quality of life after radical prostatectomy : 8-year longitudinal study in Japan. Int J Urol. 21:1220-1226

51. Ebbing J, Heckmann RC, Collins JW, Miller K, Erber B, Friedersdo F et al (2018) Oncological outcomes, quality of life outcomes and complications of partial cystectomy for selected cases of muscle-invasive bladder cancer. Sci Rep. 8(8360):1-19

Publisher's note Springer Nature remains neutral with regard to jurisdictional claims in published maps and institutional affiliations. 